\title{
EFEK PREMEDIKASI MIDAZOLAM 0,05 MG/KGBB IV TERHADAP TEKANAN DARAH dan LAJU NADI
}

\author{
${ }^{1}$ Marlin Matana \\ ${ }^{2}$ Mordekhai Laihad \\ ${ }^{2}$ Harold Tambajong \\ ${ }^{1}$ Kandidat Skripsi Fakultas Kedokteran Universitas Sam Ratulangi Manado \\ ${ }^{2}$ Bagian Ilmu Anestesi dan Reanimasi Universitas Sam Ratulangi \\ Email: marlin_chester@yahoo.com
}

\begin{abstract}
Abstrak: Operasi merupakan tindakan yang banyak menimbulkan kecemasan. Hal tersebut menyebabkan timbulnya respons stres, dengan akibat dapat terjadinya peningkatan tekanan darah dan laju nadi. Midazolam merupakan obat premedikasi yang mampu menurunkan tingkat kecemasan. Peningkatan tekanan darah dan laju nadi akibat stres psikologi sebelum menghadapi tindakan operasi, dapat mempengaruhi kondisi yang tidak menguntungkan.

Tujuan: Untuk mengetahui perubahan tekanan darah dan laju nadi pada pasien setelah premedikasi Midazolam 0,05 mg/kgbb IV. Metode penelitian: Penelitian ini merupakan penelitian analitik prospektif. Sampel ialah 25 pasien yang menjalani bedah elektif. Cara pemilihan sampel dilakukan dengan accidental sampling. Uji statitik menggunakan uji $t$ berpasangan. Hasil penelitian: Tekanan darah sistolik, diastolik, pada pasien sebelum dan sesudah premedikasi Midazolam menit ke lima dan sepuluh terdapat perbedaan yang bermakna ( $p<0,05)$, sedangkan laju nadi pasien sebelum premedikasi dan sesudah premedikasi menit ke lima dan sepuluh terdapat perbedaan yang tidak bermakna $(p>0,05)$.

Simpulan: Pemberian premedikasi Midazolam 0,05 mg/kgbb IV, dapat memperlihatkan penurunan tingkat ansietas pasien yang dapat dilihat dari penuruan tekanan darah yang bermakna namun penuruan laju nadi tidak bermakna.
\end{abstract}

Kata kunci: Midazolam 0,05 mg/kgbb iv, kecemasan, tekanan darah, laju nadi.

\begin{abstract}
Surgery is the treatment measurement thet generated a lot of anxiety. This causes the onset of the stress response, with the result can be an increase blood pressure and heart rate. Midazolam premedication is a drug that can reduce the level of anxiety. The change in pulse rate and blood pressure to be high due psychological stress, before facing surgery can affect unfavorable conditions. Purpose: To know the change of blood pressure and heart rate to patient who take premedication Midazolam 0,05 mg/kgbb IV. Methods: This research is a prospective analytical study. The sample is 25 patients who have elective surgery. Sample selection method is done by accidental sampling. Statistic test using a paired t test. Result: Systolic and diastolic blood pressure were measured in patients before and after midazolam premedication and ten minutes to five, there is a significicant difference ( $<<0,05)$, whereas the patien's heart rate before and after premedication at minute five and ten there were no significant differences ( $\mathrm{p}<0,05$ ) Conclution: By providing premedication Midazolam 0.05 $\mathrm{mg} / \mathrm{kg}$, may show decreased levels of anxiety patients that can be seen from the significant drop in blood pressure and pulse rate were not significant.
\end{abstract}

Keyword: Midazolam 0,05 mg/kgbb iv, anxiety, blood pressure, heart rate.

Pada umumnya persiapan anestesia diawali dengan persiapan psikologis/mental bagi pasien yang akan diberi anestesi. Operasi merupakan tindakan pengobatan yang banyak menimbulkan kecemasan. Kecemasan adalah sutu sinyal yang menyadarkan dan 
memperingatkan adanya bahaya yang mengancam dan memungkinkan seseorang mengambil tindakan untuk mengatasi ancaman. Kecemasan merupakan salah satu emosi yang paling menimbulkan stress yang dirasakan oleh banyak orang yang akan Menjalani operasi. Tindakan operasi atau pembedahan merupakan pengalaman yang biasa menimbulkan kecemasan, oleh karena itu berbagai kemungkinan buruk bias terjadi yang akan membahayakan pasien. Kecemasan biasanya berhubungan dengan segala macam prosedur asing yang harus dijalani pasien dan juga ancaman terhadap keselamatan jiwa akibat prosedur pem-bedahan dan tindakan pembiusan. ${ }^{1,2}$

Hasil penelitian yang dilakukan oleh Ferlina Indra S pada tahun 2002 diperoleh $80 \%$ dari 20 sampel yaitu pasien yang akan menjalani tindakan pembedahan di RS Muhammadiah Malang mengalami kecemasan. Hal ini sesuai dengan hasil observasi dan wawancara di ruang rawat bedah lantai 4 selatan IRNA B pada 6 pasien yang dirawat dengan rencana tindakan pembedahan atau operasi, diperoleh $90 \%$ dari mereka yang akan menjalani operasi mengungkapkan kecemasannya terhadap tindakan operasi yang akan dijalaninya. Bentuk kecemasan yang mereka tunjukkan seperti, pasien mengatakan takut, nyeri, tidak bisa tidur, dan khawatir jika operasi yang telah dilakukan tidak berhasil. Sebagian dari mereka mengalami peningkatan rasa cemas ketika mereka memasuki ruangan penerimaan pasien di ruang Instalasi Bedah. ${ }^{3}$

Semua respons individual terhadap stres yang baru secara langsung atau tidak langsung dipengaruhi oleh hipothalamus. Hipothalamus menerima masukan mengenai stressor fisik maupun emosi dari hampir semua daerah di otak dan dari banyak reseptor diseluruh tubuh. Sebagai respons, hipothalamus secara langsung mengaktifkan sistem saraf simpatis, mengeluarkan $\mathrm{CRH}$ untuk merangsang sekresi ACTH dan kortisol, dan memicu pengeluaran vasopresin. Sekresi aldosteron ditingkatkan oleh pengaktifan sistem renin-angiotensin-aldosteron. Medula adrenal yang mengeluarkan hormon epinefrin dan nonepinefrin ber- peran aktif pada peningkatan tekanan darah dan denyut nadi. ${ }^{4,5}$

Pengaruh psiko-emosional terhadap perubahan kardiovaskuler telah dibuktikkan oleh Brod dkk (1959). Brod dkk mengevaluasi subjek-subjeknya sebelum dan selama stress emosional akut. Selama stress ini rata-rata tekanan arterial meningkat dari $100 \mathrm{mmHg}$ sampai $120 \mathrm{mmHg}^{6}$

Penderita yang hendak masuk ke kamar operasi harus terbebas dari rasa cemas dan beberapa tujuan khusus telah tercapai dengan pemberian obat-obatan premedikasi. Salah satu tujuan premedikasi berguna meredakan kecemasan dan ketakutan. Midazolam merupakan golongan obat benzodiazepin yang biasa digunakkan untuk premedikasi...,8

Pada penelitian yang dilakukan oleh Tomoki Nishiyama (2004) midazolam dengan dosis $0,05 \mathrm{mg} / \mathrm{kgbb}$ IV sudah dapat menimbulkan efek sedasi dan antiansietas, serta dengan dosis tersebut cukup signifikan mempengaruhi penurunan tekanan darah serta laju nadi. ${ }^{9}$ Hal tersebut juga dibuktikan oleh penelitian yang di lakukan oleh Win Ni dkk ( 2005). ${ }^{10}$

Penelitian ini bertujuan untuk mengetahui adanya perubahan tekanan darah dan laju nadi sebelum dan sesudah pemberian midazolam 0,05 mg/kgbb IV. Perubahan laju nadi dan tekanan darah yang menjadi tinggi akibat stress psikologi, sebelum menghadapi tindakan operasi dapat mempengaruhi kondisi yang tidak menguntungkan. Rencana operasi yang dijadwalkan bisa saja dibatalkan akibat tekanan darah dan laju nadi yang tidak stabil tersebut, dan dapat juga mempengaruhi operator yang sedang menjalankan operasi.

\section{METODOLOGI}

Penelitian ini merupakan penelitian analitik prospektif. Sampel dalam peneltian ialah pasien yang menjalani bedah elektif. pemilihan sampel dilakukan dengan accidental sampling. Jumlah sampel sebesar 25 Pasien. Data diolah dengan komputer menggunakan program SPSS for windows seri 20 dan dinyatakan dalam nilai rerata \pm 
simpang baku (mean \pm SD). Uji statistik menggunakan uji $\mathrm{t}$ dengan derajat kemaknaan $\mathrm{p}<0,05$.

\section{HASIL}

Telah dilakukan penelitian terhadap 25 pasien yang menjalani operasi elektif di Instalansi Bedah Sentral RSUP. Prof. R. D. Kandou Manado yang memenuhi kriteria inklusi dan ekslusi selama bulan November 2012 sampai Desember 2012.

Tabel 1. Distribusi umur pasien.

\begin{tabular}{ccc}
\hline Umur & Jumlah & $\mathbf{\%}$ \\
\hline $11-20$ & 3 & 12 \\
$21-30$ & 4 & 16 \\
$31-40$ & 9 & 36 \\
$41-50$ & 5 & 20 \\
$51-60$ & 4 & 16 \\
\hline Total & $\mathbf{2 5}$ & $\mathbf{1 0 0}$ \\
\hline
\end{tabular}

Tabel 2. Distribusi berat badan pasien

\begin{tabular}{lll}
\hline Berat badan & Jumlah & \% \\
\hline $31-40$ & 2 & 8 \\
$41-50$ & 8 & 32 \\
$51-60$ & 8 & 32 \\
$61-70$ & 6 & 24 \\
$71-80$ & 1 & 4 \\
\hline Total & $\mathbf{2 5}$ & $\mathbf{1 0 0}$ \\
\hline
\end{tabular}

Kelompok umur dalam penelitian ini terbagi menjadi 5 kelompok, yakni umur 11-20 tahun, 21-30 tahun, 31-40, 41-50 tahun dan 51-60 tahun. Pada penelitian ini ditemukan pasien terbanyak adalah kelompok umur 31-40 tahun yakni sebanyak 9 orang (36\%), selanjutnya secara berturutturut pada kelompok umur 41-50 tahun (20\%), berikutnya untuk kelompok umur 21-30 tahun dan 51-60 tahun masingmasing memiliki jumlah pasien yang sama yaitu sebanyak 4 (16\%), selanjutnya umur 11-20 tahun sebanyak 3 pasien (12\%).

Distribusi berat badan dalam penelitian ini terbagi menjadi 5 kelompok, yakni berat badan $31-40 \mathrm{~kg}, 41-50 \mathrm{~kg}$, 51-60 kg, 61-70 kg dan 71-80 kg. Pada penelitian ini ditemukan pasien terbanyak adalah kelompok dengan berat badan 41-50 kg dan 51-60 kg sebanyak 8 orang (32\%), selanjutnya kelompok dengan berat badan 61-70 kg (24\%), berikutnya untuk kelompok dengan berat badan 31-40 kg sebanyak 2 orang (16\%), dan berat badan 71-80 tahun yakni 1 orang (4\%).

Pada tabel 3, pengukuran diruang operasi (sebelum premedikasi midazolam 0,05 $\mathrm{mg} / \mathrm{kgbbIV})$ didapatkan rata-rata tekanan darah sistol 125,44 mmHg dengan standar deviasi 4,984 mmHg. Pada tekanan darah sistol menit ke 5 setelah pemberian midazolam 0,05 mg/kgbb IV didapatkan rata-rata tekanan darah 122,84 dengan standar deviasi 5,273. Hasil uji didapatkan nilai 0,0005 maka dapat disimpulkan ada perbedaan bermakna antara pengukuran tekanan darah sistol di ruang operasi dan setelah 5 menit pemberian midazolam.

Untuk pengukuran tekanan darah sistol menit ke 10 setelah pemberian midazolam $0,05 \mathrm{mg} / \mathrm{kgbb} \mathrm{IV}$ didapatkan rata-rata tekanan darah 120, 92 dengan standar deviasi 5, 235. Hasil uji didapatkan nilai 0,0005 maka dapat disimpulkan ada perbedaan bermakna antara pengukuran tekanan darah sistolik di ruang operasi dan setelah 10 menit pemberian midazolam 0,05 mg/kgbb.

Tabel 3. Tekanan darah sistol sebelum dan sesudah 5 dan 10 menit.

\begin{tabular}{|c|c|c|c|c|c|}
\hline \multirow{2}{*}{$\mathrm{TD}$} & \multirow{2}{*}{ Sebelum } & \multicolumn{4}{|c|}{ Sesudah } \\
\hline & & 5 menit & Nilai p & 10 menit & Nilai p \\
\hline Sistol & $\begin{array}{c}125.44 \pm 4.983 \\
(112-133)\end{array}$ & $\begin{array}{c}122.84 \pm 5,27 \\
(108-128)\end{array}$ & 0,0005 & $\begin{array}{c}120.92 \pm 5.23 \\
(108-126)\end{array}$ & 0,0005 \\
\hline
\end{tabular}


Tabel 4. Tekanan darah diastol.

\begin{tabular}{|c|c|c|c|c|c|}
\hline \multirow[t]{2}{*}{ TD } & \multirow[t]{2}{*}{ Sebelum } & \multicolumn{4}{|c|}{ Sesudah } \\
\hline & & 5 menit & Nilai p & 10 menit & Nilai p \\
\hline diastol & $\begin{array}{l}82.04 \pm 7.231 \\
(63-92)\end{array}$ & $\begin{array}{l}78.8 \pm 6.071 \\
(63-85)\end{array}$ & 0,002 & $\begin{array}{l}76 \pm 6.910 \\
(63-85)\end{array}$ & 0,0005 \\
\hline
\end{tabular}

Tabel 5. Laju nadi.

\begin{tabular}{|c|c|c|c|c|c|}
\hline & \multirow[t]{2}{*}{ Sebelum } & \multicolumn{4}{|c|}{ Sesudah } \\
\hline & & 5 menit & Nilai p & 10 menit & Nilai p \\
\hline Laju nadi & $\begin{array}{l}82.6 \pm 9.073 \\
(69-107)\end{array}$ & $\begin{array}{l}82.36 \pm 5.098( \\
69-94)\end{array}$ & 0,892 & $\begin{array}{l}81.52 \pm 5.895 \\
(65-94)\end{array}$ & 0,557 \\
\hline
\end{tabular}

Pada tabel 4, untuk pengukuran di ruang operasi (sebelum premedikasi midazolam $0,05 \mathrm{mg} / \mathrm{kgbb} \mathrm{IV}$ ), didapatkan ratarata tekanan darah diastol $82,4 \mathrm{mmHg}$ dengan standar deviasi 7,231 mmHg. Pada tekanan darah diastol menit ke 5 setelah pemberian midazolam $0,05 \mathrm{mg} / \mathrm{kgbb} \mathrm{IV}$ didapatkan rata-rata tekanan darah 78,8 dengan standar deviasi 6,701. Hasil uji didapatkan nilai 0,002 maka dapat disimpulkan ada perbedaan bermakna antara pengukuran tekanan darah diastol di ruang operasi dan setelah 5 menit pemberian midazolam. Untuk pengukuran tekanan darah diastol menit ke 10 setelah pemberian midazolam 0,05 mg/kgbb IV didapatkan rata-rata tekanan darah 76 dengan standar deviasi 6,910. Hasil uji didapatkan nilai 0,0005 maka dapat disimpulkan ada perbedaan bermakna antara pengukuran tekanan darah distolik di ruang operasi dan setelah 10 menit pemberian midazolam $0,05 \mathrm{mg} / \mathrm{kgbb}$ iv.

Pada Tabel 6, pengukuran diruang operasi (sebelum premedikasi midazolam 0,05 $\mathrm{mg} / \mathrm{kgbb} \mathrm{IV}$ ), didapatkan rata-rata laju nadi 82,6 mmHg dengan standar deviasi 9,073. Pada laju nadi menit ke 5 setelah pemberian midazolam 0,05 $\mathrm{mg} / \mathrm{kgbb}$ IV didapatkan rata-rata laju nadi 82,36 dengan standar deviasi 5,09, hasil uji didapatkan nilai 0,892. Maka dapat disimpulkan ada perbedaan tapi tidak bermakna karena nilai antara pengukuran tekanan darah laju nadi sebelum dan setelah 5 menit pemberian midazolam. Untuk pengukuran tekanan da-rah laju nadi menit ke 10 setelah pemberian midazolam 0,05 $\mathrm{mg} / \mathrm{kgbb}$ IV didapatkan rata- rata tekanan darah 81,52 dengan standar deviasi 5,895. Hasil uji didapatkan nilai 0,557 maka dapat disimpulkan ada perbedaan tapi tidak bermakna antara pengukuran laju nadi di ruang operasi dan setelah 10 menit pemberian midazolam $0,05 \mathrm{mg} / \mathrm{kg}$ bb iv.

\section{PEMBAHASAN}

Pada tabel 4 Tekanan darah sistol, Hasil yang didapatkan, sesuai dengan hipotesis Penulis, yang menyatakan terjadi perubahan tekanan darah yang menurun secara bermakna pada pasien yang menjalani premedikasi midazolam $0,05 \mathrm{mg} / \mathrm{kgbb}$ dibandingkan dengan pasien sebelum premedikasi. Penelitian yang dilakukan penulis mempunyai nilai yang bermakna dengan penelitian yang dilakukan oleh Tomoki Nishiyama (2004) yang membuktikan bahwa midazolam dengan dosis $0,05 \mathrm{mg} / \mathrm{kg}$ bb sudah dapat menurunkan tekanan darah secara bermakna. ${ }^{9}$

Tekanan Darah Sistolik (TDS) menunjukkan tekanan pada arteri bila jantung berkontraksi (denyut jantung) atau tekanan maksimum dalam arteri pada suatu saat. TDS dinyatakan oleh angka yang lebih besar jika dibaca pada alat pengukur tekanan 
darah. TDS normal 90-120 mmHg. ${ }^{10}$

Kecemasan yang terjadi pada seorang individu dapat ditemui pada pasien yang sebelum menjalani tindakan operasi. Komponen-komponen yang terlibat saat seseorang merasa cemas adalah komponen kognitif, somatik, emosional dan behavior. Kecemasan mempunyai gejala baik secara fisiologis, emosional, maupun kognitif. Gejala cemas fisiologis meliputi peningkatan frekuensi nadi, peningkatan tekanan darah, peningkatan pernafasan, mata bergetar, gemetar. Pada penelitian yang dilakukan oleh penulis rata-rata pasien yang menjalani operasi di IBS, tekanan darah mereka mengalami peningkatan. Penelitian ini mempunyai kesamaan dengan penelitian yang dilakukan oleh Ferlina Indra S ( 2002 ) diperoleh dari 20 sampel yaitu pasien yang akan menjalani tindakan pembedahan di RS Muhammadiah Malang mengalami kecemasan. ${ }^{3}$

Penderita yang hendak masuk ke kamar operasi harus terbebas dari rasa cemas dan beberapa tujuan khusus telah tercapai dengan pemberian obat-obatan premedikasi. Salah satu tujuan premedikasi berguna meredakan kecemasan dan ketakutan. Biasa obat yang digunakkan adalah midazolam yang merupakan golongan obat benzodiazepin. ${ }^{7,8}$

Pada tabel 5 Tekanan darah diastolik, Hasil yang didapatkan sesuai dengan hipotesis Penulis, yang menyatakan terjadi perubahan tekanan darah yang menurun secara bermakna pada pasien yang menjalani premedikasi midazolam 0,05 mg/kgbb dibandingkan dengan pasien sebelum premedikasi. Tekanan darah diastolik adalah adalah tekanan darah pada saat jantung tidak sedang berkonstraksi atau beristirahat.

Penurunan tekanan darah ini mungkin dapat disebabkan oleh efek langsung dari midazolam yang menyebabkan vasodilatasi. Mekanisme yang mendasari terjadinya vasodilatasi melibatkan peran dari terganggunya transmembaran dengan masuknya arus $\mathrm{Ca}^{++}$. mekanisme ini mirip dengan antagonis dari $\mathrm{Ca}^{++}$dan peningkatan sintesis Nitrat Oksida di endothelium. Efek negatif dari inotropik yang melibatkan midazolam disebabkan oleh penghambatan L-Type $\mathrm{Ca}^{++}$channel. Oleh karena itu beberapa penulis mengingatkan pemakaian midazolam hati-hati digunakan pada pasien dengan hipovolemia atau gangguan fungsi ventrikel kiri. ${ }^{12}$

Pada Tabel 6 laju nadi, Hasil uji didapatkan nilai 0,557 maka dapat disimpulkan ada perbedaan tapi tidak bermakna antara pengukuran laju nadi di ruang operasi dan setelah pemberian midazolam 0,05 mg/kgbb. Pada penelitian sebelumnya yang dilakukan oleh Sun dkk (2008) pemberian midazolam untuk premedikasi digunakkan dosis 0,06 $\mathrm{mg} / \mathrm{kgbb}$ iv pada 30 pasien. Hasil yang ditemukan pada laju nadi terdapat perbedaan tapi tidak bermakna karena nialai $p=0,66$. $^{13}$

Kelemahan dari penelitian ini ialah dalam penelitian tidak menggunakan pengukuran tingkat kecemasan (Visual Analog Scale ) serta faktor penyebab tidak diteliti karena keterbatasan waktu.

\section{SIMPULAN DAN SARAN}

Simpulan Pemberian premedikasi midazolam 0,05 mg/kgbb IV, dapat memperlihatkan penurunan tingkat ansietas pasien yang dapat dilihat dari penuruan tekanan darah yang bermakna namun penuruan laju nadi tidak bermakna

\section{SARAN}

1. Pemberian midazolam $0,05 \mathrm{mg} / \mathrm{kg}$ bb sudah dapat menurunkan tingkat anxietas yang dilihat dari penurunan tekanan darah.

2. Perlu dilakukan penelitian kembali dengan lebih memperhitungkan Penilaian tingkat kecemasan (Visual analog scale).

3. Faktor-faktor penyerta seperti pengalaman masa lampau saat operasi, Kultural serta jenis kelamin yang dapat mempengaruhi tekanan darah dan laju nadi harus ditambahkan.

\section{UCAPAN TERIMAKASIH}

Penulis berterima kasih kepada Dr. dr. A. A. Pontoh Wuwungan, SpAn, dr. Lucky 
Kumaat, SpAn selaku penguji I dan penguji II. Tidak lupa pula kepada dr. Mordekhai Laihad, M.kes, SpAn dan dr. Harold Tambajong SpAn selaku pembimbing I dan pembimbing II, serta kepada semua pihak baik secara langsung maupun tidak langsung telah menumbuhkan ide atau gagasan pada penulis.

\section{DAFTAR PUSTAKA}

1. Paryanto. Perbedaan tingkat kecemasan pasien pre operatif Selama menunggu jam operasi antara ruang rawat inap dengan ruang persiapan operasirRumah sakit ortopedi surakarta [Skripsi]. Surakarta ; Universitas Muhammadiyah Surakarta;2009.

2. Kaplan HI, Sadock BJ, Greb JA. Kaplan sadock synopsis psikitri. Edisi 2. Tanggerang: BINARUPA AKSARA, 2010; p.19.

3. Nyi dewi kuraesin. Faktor-faktor yang brhubungan dengan tingkat Kecemasan pasien yang akan menjalani operasi mayor elektif di Ruang rawat bedah rsup fatmawati - Jakarta selatan. [Skripsi]. November 2009.

4. Sherwood L. Fisiologi manusia dari sel ke sistem. Edisi 2. Jakarta: EGC; 2001.p.659-61.

5. Takhasi T, Ikeda K, Kitamura N, Tsukasaki T, Nakama Daisuke, kameda T. Anxiety, reactivity, and social stress-induced cortisol elevation in humans. Japan; 2005.p.351-4.

6. Brod J, Fence V, Hegi K, Jikka J. During acute emosional stress( mental arithmetic) in Normotensive and hypertensive subjects. Clin Sic. 1959.18. 269-279.

7. Wichiniak A, Brunner $H$, Marcus Ising, Gil PF, Holsboer F, Friess E. Impaired hypothalamic Ptituitaryadrenocortical (HPA ) system is related to severity on benzodiazepine withdrawal Patients with depression. Poland:2003.p.1101-8

8. Wildschut DE, Vet NJ, de wildt SN. Application To Add Midazolam To The Model List Of Essential Medicines. Netherland: 2010

9. Nishiyama T. Dose-finding study of intravenous midazolam for sedation and amnesia during spinal anesthesia in patiens premedicated with intramuscular midazolam. Japan: 2004.p.254-261.

10. Win N. Nini, Fukuyama $H$, Kohase Hikaru. The Different Effects Of Intravenous Propofol and Midazolam Sedation On Hemodynamic And Heart Rate Variabilitty. Japan: 2005.p.97-102.

11. Klabunde RE. 2007. Cardiovasculary physiology concepts. Tersedia : http://www.cvphysiology.com/Blood\% 20Pressure/BP001.htm

12. Khan HZ, Saberi MDH, Bitaraf MA. The dilemma of hemodynamic Instability during Induction of Anesthesia: Can midazolam serve as a suitable Substitute for thiopentone. Iran: 2003.p.186.

13. Sun GC, Hsu MC, Chia Y, Chen YP, Shaw ZF. Effects of age and gender on intravenous midazolam premedication. Taiwan;2008.p.636. 